\title{
The tricuspid valve: If it's not broken, don't fix it
}

\author{
Marc Gillinov, MD, Stephanie Mick, MD, Kenneth McCurry, MD, and Jose Navia, MD
}

\footnotetext{
From the Department of Thoracic and Cardiovascular Surgery, Cleveland Clinic, Cleveland, Ohio.

Disclosures: M.G. serves as a consultant to Edwards Lifesciences, Medtronic, St Jude Medical, and Abbott and receives research funding from Tendyne and St Jude Medical. S.M. serves as a consultant to Medtronic. All other authors have nothing to disclose with regard to commercial support.

Received for publication Jan 11, 2017; accepted for publication Jan 12, 2017; available ahead of print March 1, 2017.

Address for reprints: Marc Gillinov, MD, Department of Thoracic and Cardiovascular Surgery, Cleveland Clinic, Desk J4-1, 9500 Euclid Ave, Cleveland, OH 44195 (E-mail: gillinom@ccf.org).

J Thorac Cardiovasc Surg 2017;154:108-9

$0022-5223 / \$ 36.00$

Copyright $(\underset{0}{ } 2017$ by The American Association for Thoracic Surgery

http://dx.doi.org/10.1016/j.jtcvs.2017.01.022
}

Recent publications and presentations have ignited controversy regarding the management of the tricuspid valve at the time of mitral valve surgery for degenerative disease. ${ }^{1-5}$ Although severe tricuspid regurgitation (TR) is uncommon in this patient population, some surgeons add a tricuspid valve procedure to most of their mitral valve operations. ${ }^{1}$ Others, including David and colleagues ${ }^{2}$ in Toronto and our own group at the Cleveland Clinic, ${ }^{6}$ believe that a minority of patients undergoing mitral valve procedures require concomitant tricuspid valve surgery.

In their article in this issue of the Journal examining the surgical outcomes in more than 1000 patients who underwent mitral valve repair for degenerative disease, David and colleagues $^{7}$ concluded that (1) only $11.8 \%$ had TR that was moderate or greater at their presentation, (2) patients with TR were older and had more advanced structural heart disease and reduced long-term survival, (3) moderate or severe TR in follow-up was uncommon but more likely in those with preoperative TR, and (4) moderate or severe TR should be addressed at the time of mitral valve surgery. This work, combined with previous research, provides provisional answers to important questions concerning the management of TR in patients with degenerative mitral valve disease.

\section{WHEN IS THE TRICUSPID VALVE BROKEN?}

The tricuspid valve should be considered broken and in need of repair when, on a preoperative echocardiogram, (1) TR is graded as moderate or greater, or (2) TR is mild and the tricuspid annular dimension exceeds $40 \mathrm{~mm}$. In both these instances, the valve exhibits dysfunction. Although some favor a tricuspid valve procedure (we refrain from using the word "repair" here), for those with annular dilatation and no valvular dysfunction, ${ }^{1,5}$ that strategy currently appears overly aggressive.

\section{WHAT PERCENTAGE OF PATIENTS WITH MITRAL VALVE DISEASE SHOULD UNDERGO TRICUSPID VALVE REPAIR?}

A minority of patients with degenerative mitral valve disease require concomitant tricuspid valve surgery. David and abandoned.

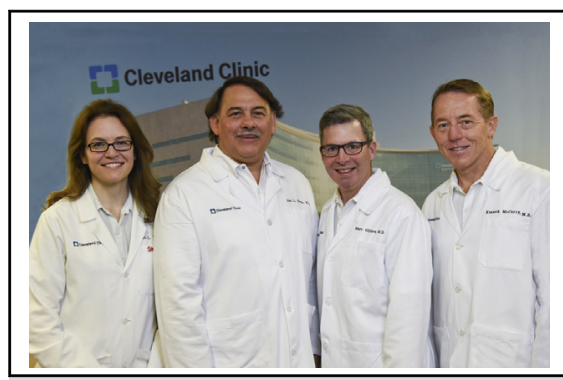

Left to right. Drs Stephanie Mick, Jose Navia, Marc Gillinov, and Kenneth McCurry.

\section{Central Message}

In patients with degenerative mitral valve disease, the tricuspid valve should be addressed if tricuspid regurgitation is (1) moderate or greater or (2) mild with annular dilatation.

See Article page 110

colleagues $^{7}$ and others note that fewer than $15 \%$ of patients undergoing mitral valve procedures present with TR graded as moderate or severe; such patients have been referred late in their course. Ideally, the patient with mitral valve disease will come to surgery before the development of TR, because the presence of TR is a marker for more advanced cardiac disease and is associated with diminished long-term survival, even when addressed by tricuspid annuloplasty.

\section{HOW SHOULD THE TRICUSPID VALVE BE REPAIRED?}

When tricuspid annuloplasty is used to address functional $\mathrm{TR}$, a rigid, undersized, nonplanar ring is most effective. Suture annuloplasty (eg, DeVega annuloplasty) is an outmoded operation that is less successful and should be

\section{DO WE NEED MORE DATA?}

At this point, our management of TR is based on retrospective clinical series. We need a definitive, randomized, controlled clinical trial to settle this controversy. Such a trial is currently enrolling. The Cardiothoracic Surgical Trials Network will randomly assign 400 patients with degenerative mitral valve disease with either (1) moderate TR or (2) tricuspid annular dilatation $(\geq 40 \mathrm{~mm})$ and TR graded as trace or mild to undergo either mitral valve surgery alone or mitral valve surgery plus a rigid, nonplanar, undersized tricuspid annuloplasty. The primary end point is a composite of death, reoperation for TR, development of severe TR, 
or progression of TR by 2 grades in the first 24 months after surgery. Until completion of this trial, the preponderance of data supports the adage, "If it's not broken (TR moderate or greater, or mild TR with annular dilatation), don't fix it."

\section{References}

1. Chikwe J, Itagaki S, Anyanwu A, Adams DH. Impact of concomitant tricuspid annuloplasty on tricuspid regurgitation, right ventricular function, and pulmonary artery hypertension after repair of mitral valve prolapse. J Am Coll Cardiol. 2015;65:1931-8.

2. David TE, David CM, Manlhiot C. When is tricuspid annuloplasty necessary during mitral valve surgery? J Thorac Cardiovasc Surg. 2015;150:1043-4.

3. Dion RA. Is the air in Toronto, Rochester, and Cleveland different from that in London, Monaco, Leiden, Genk, Milan, and New York? J Thorac Cardiovasc Surg. 2015;150:1040-3.
4. Yilmaz O, Suri RM, Dearani JA, Sundt TM III, Daly RC, Burkhart HM, et al Functional tricuspid regurgitation at the time of mitral valve repair for degenerative leaflet prolapse: the case for a selective approach. J Thorac Cardiovasc Surg. 2011;142:608-13.

5. Dreyfus GD, Corbi PJ, Chan KM, Bahrami T. Secondary tricuspid regurgitation or dilatation: which should be the criteria for surgical repair? Ann Thorac Surg. 2005; 79:127-32.

6. Navia JL, Brozzi NA, Klein AL, Ling LF, Kittayarak C, Nowicki ER, et al. Moderate tricuspid regurgitation with left-sided degenerative heart valve disease: to repair or not to repair? Ann Thorac Surg. 2012;93:59-67; discussion 68-9.

7. David TE, David CM, Fan CP, Manlhiot C. Tricuspid regurgitation is uncommon after mitral valve repair for degenerative diseases. J Thorac Cardiovasc Surg. 2017;154:110-22.e1.

8. Navia JL, Nowicki ER, Blackstone EH, Brozzi NA, Nento DE, Atik FA, et al. Surgical management of secondary tricuspid valve regurgitation: Annulus, commissure, or leaflet procedure? J Thorac Cardiovasc Surg. 2010;139:1473-82.e5. 